\title{
CONSTITUIÇÃO DE UMA ESCOLA INCLUSIVA: ANÁLISE COMPARATIVA ENTRE PROJETO POLÍTICO PEDAGÓGICO, PLANO MUNICIPAL DE EDUCAÇÃO E PLANO NACIONAL DE EDUCAÇÃO.
}

Ana Mayra Samuel da Silva ${ }^{1}$, Elisa Tomoe Moriya Schlünzen ${ }^{1}$, Danielle Aparecida do Nascimento dos Santos ${ }^{2}$, Ana Virginia Isiano Lima ${ }^{1}$.

\footnotetext{
${ }^{1}$ Universidade Estadual Paulista - UNESP, Programa de Pós-Graduação em Educação, Presidente Prudente, SP. ${ }^{2}$ Universidade do Oeste Paulista - UNOESTE, Programa de Pós-Graduação Lato Sensu, Presidente Prudente, SP. E-mail: E-mail: ana.mayra.ss@gmail.com. Agência Financiadora: Coordenação de Aperfeiçoamento de Pessoal de Nível Superior (CAPES)
}

\section{RESUMO}

Para constituirmos uma escola inclusiva, que reconheça e valorize as diferenças, além de fornecer condições de acesso e permanência de todos na escola comum, a gestão escolar tem papel fundamental. O objetivo deste estudo, baseado em uma pesquisa de mestrado, é analisar comparativamente algumas políticas públicas educacionais que tangem o processo de inclusão, de acordo com os princípios da Educação Inclusiva. A abordagem metodológica da pesquisa é qualitativa. Os participantes são membros da equipe gestora: diretora escolar, vice-diretora escolar e coordenadora pedagógica; compreendendo três participantes, de uma escola pública localizada no interior do oeste paulista. Na coleta de dados foram realizadas análises documentais sobre o Projeto Político Pedagógico (PPP), o Plano Municipal de Educação (PME) e o Plano Nacional de Educação (PNE). Diante da análise é possível concluir preliminarmente que existe a necessidade de adequação do PME, e, consequentemente do PPP, em relação ao PNE, a fim de atingir a Meta 4 referente à inclusão escolar. A pesquisa revela, também, que a equipe gestora, quando aberta a um processo democrático, pode desenvolver ações para a efetivação dos princípios da educação inclusiva, por meio da articulação intersetorial.

Palavras-Chave: Inclusão Escolar, Gestão Escolar, Políticas Públicas Educacionais, Projeto Político Pedagógico, Plano Municipal de Educação, Plano Nacional de Educação.

\section{CONSTITUTION OF AN INCLUSIVE SCHOOL: COMPARATIVE ANALYSIS BETWEEN PEDAGOGICAL POLITICAL PROJECT, MUNICIPAL PLAN OF EDUCATION AND NATIONAL EDUCATION PLAN}

\begin{abstract}
In order to constitute an inclusive school that recognizes and values differences, in addition to providing conditions for access and permanence of all in the common school, school management plays a fundamental role. The purpose of this study, based on a master's research, is to comparatively analyze some public educational policies that affect the inclusion process, in accordance with the principles of Inclusive Education. The methodological approach of the research is qualitative. Participants are members of the management team: school director, school vice principal and pedagogical coordinator; comprising three participants, from a public school located in the interior of western São Paulo. In the collection of data, documentary analyzes were carried out on the Political Educational Project (PPP), the Municipal Education Plan (PME) and the National Education Plan (PNE). In view of the analysis, it is possible to preliminarily conclude that there is a need to adapt the PME, and consequently of the PPP, in relation to the PNE, in order to achieve Goal 4 regarding school inclusion. The research also reveals that the management team,
\end{abstract}


when open to a democratic process, can develop actions for the realization of the principles of inclusive education, through intersectoral articulation.

Keywords: School Inclusion, School Management, Public Educational Policies, Political Pedagogical Project, Municipal Education Plan, National Education Plan.

\section{INTRODUÇÃO}

A aceitação e a valorização de todas as pessoas, de acordo com suas especificidades, é pressuposto da educação escolar atual, em todo o mundo. Essa educação deve estar direcionada ao desenvolvimento de um processo inclusivo. A gestão escolar tem um papel fundamental para a organização da escola, bem como para a transformação e melhoramento da sua estrutura em termos dos paradigmas da inclusão.

Nessa perspectiva, entender a escola como um espaço satisfatório para convívio com as diferenças nos permite compreender o conceito de Educação Inclusiva. Segundo a Organização das Nações Unidas para a Educação, a Ciência e a Cultura (UNESCO),

Um conceito alargado de Educação Inclusiva pode ser concebido como um princípio e uma orientação geral para fortalecer a educação, com vista a um desenvolvimento sustentável, aprendizagem ao longo da vida para todos e acesso igual de todos os níveis da sociedade às oportunidades de aprendizagem. (UNESCO, 2008, p. 22)

Para que esse conceito se efetive em nossas escolas, é importante que a equipe gestora apoie as práticas inovadoras e saiba buscar apoio dos diferentes setores, por meio de um trabalho colaborativo junto a equipes intersetorias para a melhoria da escola, desenvolvendo uma estrutura compartilhada entre educadores, profissionais e famílias. Esse apoio é denominado pela Política Nacional de Educação Especial na perspectiva da Educação Inclusiva (2008) como intersetorialidade, ou seja, pode se deflagrar mediante um trabalho colaborativo realizado entre equipes intersetorias: gestores, educadores, profissionais da área social, saúde e famílias.

Um movimento de gestão escolar mais democrática e aberta, que tenda a viabilizar a formação dos profissionais atuantes na escola, além de uma preparação do ambiente escolar no que diz respeito ao convívio com as diferenças, pode caracterizar a intersetorialidade. A escola pode se adequar para um atendimento mais efetivo e comprometido com os indivíduos, adicionando princípios pedagógicos válidos para todos os estudantes, o que resultará naturalmente na inclusão escolar.

De acordo com a Política Nacional de Educação Especial na Perspectiva da Educação Inclusiva (2008), para assegurar a intersetorialidade se faz necessário o desenvolvimento de projetos em parceria com outras áreas, visando propor um amplo e efetivo atendimento aos estudantes público-alvo da Educação Especial, por profissionais da área da saúde, ações de assistência social, inserção no mercado de trabalho e justiça, além do apoio familiar.

O papel da equipe gestora escolar no processo de inclusão é exercer um trabalho coletivo e colaborativo, que envolva discussões e ações sobre os desafios e possibilidades que as políticas públicas oferecem às escolas, refletindo, sempre, sobre a escola que queremos construir e os indivíduos que podemos formar.

Vale lembrar que, a educação inclusiva é uma conquista diária para a escola e para os que dela fazem parte, e, para chegar ao ideal, devemos trabalhar com o que é possível. $E$, a escola precisa ser reorganizada como um todo, a fim de que o trabalho seja realmente, articulado, colaborativo e todos possam desempenhar seu papel para contribuir uma educação cada vez mais inclusiva.

A partir dessas premissas, a pesquisa de Mestrado intitulada "Gestão Escolar: os desafios vivenciados para a consolidação da intersetorialidade em uma perspectiva inclusiva" tem como 
objetivo analisar, as estratégias desenvolvidas pela equipe gestora de uma escola de educação básica pública para a articulação intersetorial visando melhorar o processo de inclusão, de acordo com os princípios da Educação Inclusiva.

A pesquisa tem vigência de 2016 a 2018, é financiada pela Coordenação de Aperfeiçoamento de Pessoal de Nível Superior (CAPES), e está inserida na linha de pesquisa Processos Formativos, Ensino e Aprendizagem do Programa de Pós-Graduação em Educação da Universidade Estadual Paulista "Júlio de Mesquita Filho", campus de Presidente Prudente/São Paulo/Brasil. Neste artigo pretende-se analisar comparativamente algumas políticas públicas educacionais que tangem o processo de inclusão, de acordo com os princípios da Educação Inclusiva.

\section{METODOLOGIA}

A abordagem metodológica da pesquisa é qualitativa, pois conforme Richardson $(2012, p$. $80)$

Os estudos que empregam uma metodologia qualitativa podem descrever a complexidade de determinado problema, analisar a interação de certas variáveis, compreender e classificar processos dinâmicos vividos por grupos sociais, contribuir no processo de mudança de determinado grupo e possibilitar, em maior nível de profundidade, o entendimento das particularidades do comportamento dos indivíduos.

Por meio da abordagem qualitativa, é possível entender a natureza de um fenômeno social e buscar soluções teóricas e práticas para situação vivenciada. A partir de abordagem qualitativa, a pesquisa é comprometida com o acompanhamento e análise sobre as ações da equipe gestora de uma escola pública.

A pesquisa tem autorização ética mediante cadastro no Comitê de Ética e Pesquisa, (CAAE): 55532916.0.0000.5402. O contexto de pesquisa é uma escola municipal de ensino fundamental situada em um município brasileiro do interior paulista de pequeno porte. A escola atende estudantes do 1을 ao ano do Ensino Fundamental. Atualmente funciona em dois períodos (matutino e vespertino), com aproximadamente trezentos e oitenta estudantes matriculados ${ }^{1}$. Os participantes são membros da equipe gestora, compreendendo: diretora escolar, vice-diretora escolar e coordenadora pedagógica.

De acordo com Lüdke e André (1986, p. 38) a análise documental "pode se constituir numa técnica valiosa de abordagem de dados qualitativos, seja completando as informações obtidas por outras técnicas, seja desvelando aspectos novos de um tema ou problema". A análise documental, utilizada como fase exploratória na pesquisa, permitiu a identificação de informações relevantes sobre a maneira como a instituição se configura. Assim, foram analisados o Projeto Político Pedagógico (PPP) da instituição, o Plano Municipal de Educação (PME) e o Plano Nacional de Educação (PNE).

\section{RESULTADOS}

A equipe gestora da escola pública de educação fundamental, localizada em um município brasileiro do interior paulista de pequeno porte, procurou os pesquisadores do Grupo de Pesquisa "Ambientes Potencializadores para Inclusão" (API) buscando receber orientações para melhoria do processo de inclusão na sua escola, devido vivencias anteriores com participantes do grupo.

Inicialmente a equipe gestora, representada pela diretora, apontou as dificuldades em incluir determinados estudantes com deficiência ou com dificuldade de aprendizagem e a

\footnotetext{
${ }^{1}$ Informações extraídas do Projeto Político Pedagógico (PPP) da Unidade Escolar.
} 
necessidade reconhecida em de rever o seu papel para conseguir recursos, estratégias e formar a comunidade escolar. No momento de diálogo sobre essas dificuldades e necessidades a pesquisadora, disponibilizou-se em apoiar a equipe gestora.

Considerando uma análise aprofundada sobre o documento da Política Nacional de Educação Especial na perspectiva da Educação Inclusiva de 2008 e o lócus da gestão escolar estabelecido no documento, optou-se por compreender inicialmente as possibilidades da articulação dos diferentes setores e o papel da equipe gestora no processo formativo da comunidade, visando a inclusão efetiva dos estudantes público-alvo da educação especial matriculados na unidade escolar.

Foram analisados o PPP, o PME, e o PNE com o intuito de compreender os objetivos da unidade escolar, seu conceito de inclusão escolar adotado, entre outras peculiaridades que permitiram começar a compreender a realidade da escola.

O PPP da unidade escolar supracitada foi elaborado a partir do contexto de uma pesquisa de IC sobre gestão escolar. O documento alega que sua construção teve como participantes a envolveu: gestão escolar, professores, funcionários e pesquisadoras. Em relação ao conceito de inclusão escolar e as ações desenvolvidas pela escola e pela equipe gestora para promove-la, o PPP da unidade escolar, afirma que,

a inclusão é um desafio permanente nos nossos dias. Nesse sentido, trabalhar na perspectiva da inclusão de forma ampla significa oferecer múltiplas e sempre singulares condições para o crescimento e aprendizagem de cada aluno. É necessário formular políticas de inclusão e projetos político-pedagógicos que contemplem a diversidade e incluam as crianças, jovens e adultos da nossa Rede Municipal de Ensino, considerando as diferenças dos sujeitos e as especificidades de suas culturas e aprendizagens, garantindo a equiparação de oportunidades (PPP, 2015, p. 11).

Assim, se faz necessário considerar as diferenças dos estudantes, suas especificidades, suas culturas, seus diferentes modos e tempos de aprender, garantindo, dessa maneira a equiparação de oportunidades e permanência estudantil, conforme preconiza a Constituição Federal de 1988.

Destaca-se que o PPP não evidencia objetivos e metas que tenham por finalidade melhorar o processo de inclusão escolar. O documento não aborda a acessibilidade arquitetônica e pedagógica, oferta de atendimento educacional especializado e o desenvolvimento da intersetorialidade, itens presentes no corpo da Política Nacional de Educação Especial na Perspectiva da Educação Inclusiva (BRASIL, 2008). Ao considerar a inclusão como um desafio, conforme exposto no PPP, esperava-se que os participantes da elaboração do PPP elencassem objetivos e metas para sua superação.

O texto do PME (Lei 2.372/ 2014), afirma que elaboração contou com a participação de dirigentes de entidades e instituições de ensino locais. De acordo com o relato das três gestoras participantes desse estudo, houve momentos de trocas e partilhas de informações com gestores escolares e educacionais de outros municípios do oeste paulista para elaboração do PME. Uma vez que o contexto em que esse documento foi elaborado, outros municípios também estavam passando pelo processo de reformulação a fim de atender as novas exigências do PNE.

O PME revela a preocupação do município em propor

uma escola integradora, inclusiva, aberta à diversidade dos alunos, no que a participação da comunidade é fator essencial. A Educação especial, como modalidade de educação escolar, terá que ser promovida sistematicamente nos diferentes níveis de ensino. A garantia de vagas no ensino regular para os diversos graus e tipos de deficiência é uma medida 
importante. Requer-se um esforço determinado das autoridades educacionais para valorizar a permanência dos alunos nas classes regulares, eliminando a nociva prática de encaminhamento para classes especiais daqueles que apresentam dificuldades comuns de aprendizagem, problemas de dispersão de atenção ou de disciplina. A esses deve ser dado maior apoio pedagógico nas suas próprias classes, e não separá-los como se precisassem de atendimento especial (PME, 2014, p. 63).

Percebe-se que o documento apresenta a educação especial da mesma maneira que o art. 59 da Lei de Diretrizes e Bases da Educação Nacional (LDBEN), Lei 9.304/96, como uma modalidade de ensino transversal presente nas demais níveis, modalidades e etapas da educação. O encaminhando de estudantes público-alvo da educação especial para classes e instituições especializadas ainda é um desafio polêmico neste município. Visto que, o quadro de professores atuantes nas escolas, e, especificamente na escola em que a pesquisa foi realizada, ainda defendem essa atitude e a relevam por meio de suas práticas pedagógicas em sala de aula.

Ao contrário do PPP, o PME elenca oito objetivos e metas que devem ser desenvolvidos, durante os anos de sua vigência, em âmbito municipal a curto, médio e longo prazo. Dentre esses objetivo e metas, pode-se elencar a implementação do AEE e da SRM. Algumas nuances de articulação intersetorial são mencionadas, mas, no entanto, se limitam apenas à aplicação de testes de acuidade visual e auditiva em estudantes da rede municipal de educação. Não abordando assim a intersetorialidade ou articulação intersetorial como uma prática ou objetivo para se promover a inclusão.

O PNE (Lei no 13.005/2014) estabelece na Meta 4 seu objetivo em,

universalizar, para a população de 4 (quatro) a 17 (dezessete) anos com deficiência, transtornos globais do desenvolvimento e altas habilidades ou superdotação, o acesso à educação básica e ao atendimento educacional especializado, preferencialmente na rede regular de ensino, com a garantia de sistema educacional inclusivo, de salas de recursos multifuncionais, classes, escolas ou serviços especializados, públicos ou conveniados (BRASIL, 2014, p.9)

$E$, além disso, estabelece dezenove estratégias, para alcançar o objetivo supracitado, dessa forma, cabe aos gestores escolares e educacionais estaduais e municipais desenvolvê-las, diante dos desafios, das realidades e das possibilidades das escolas públicas, para se adequar ao exposto no plano.

Diante da análise de ambos os documentos, PPP, PME e PNE, vale destacar que a comparação sobre o conceito de inclusão, objetivo e metas foi apresentado à Divisão Municipal de Educação, que encaminhou ao Conselho Municipal de Educação, solicitando a participação da pesquisadora e das três gestoras escolares participantes do estudante, para compor uma reunião. A pauta desta reunião foi a organização e a formação de uma comissão que se propusesse a estudar profundamente ambos os documentos novamente, com o intuito de rever e reformular o PME, uma vez que precisa estar de acordo com as exigências pré-estabelecidas nos objetivos e metas do PNE.

Considerando o resultado satisfatório obtido por meio da reflexão gerada sobre documentos importantes que regem o funcionamento administrativo e pedagógico das unidades escolares, a equipe gestora escolar, ainda em seu processo reflexivo, considerou importante e válido participar desta comissão e, assim propor mudanças no PPP da unidade escolar, visando acrescentar novas ações desenvolvidas para promoção da inclusão, que estejam de acordo com os documentos legais que regem a educação brasileira. 


\section{DISCUSSÃO}

A escola regular atual assume o compromisso de desenvolver e promover um processo de ensino e aprendizagem de qualidade a todos os estudantes que a frequentam. Porém, para que todos sejam acolhidos e atendidos de acordo com as suas necessidades e especificidades, os objetivos propostos pela educação escolar devem estar direcionados a conhecer os estudantes e, por isso, estabelecer relações afetivas com os mesmos.

Conforme o Ministério da Educação (MEC), a escola deve ser considerada com um, [...] espaço no qual se deve favorecer, a todos os cidadãos, o acesso ao conhecimento e o desenvolvimento de competências, ou seja, a possibilidade de apreensão do conhecimento historicamente produzido pela humanidade e de sua utilização no exercício efetivo da cidadania. É no dia-a-dia escolar que crianças e jovens, enquanto atores sociais, têm acesso

aos diferentes conteúdos curriculares, os quais devem ser organizados de forma a efetivar a aprendizagem. Para que este objetivo seja alcançado, a escola precisa ser organizada de forma a garantir que cada ação pedagógica resulte em uma contribuição para o processo de aprendizagem de cada aluno (BRASIL, 2004, p.7).

A partir desta perspectiva, insere-se o papel democrático da escola e as políticas públicas educacionais sobre a educação especial na perspectiva da educação inclusiva. Martins (2006, p. 14) explica que a proposta de inclusão dos estudantes público-alvo da educação especial, em escolas da rede regular de ensino compreende,

a educação como um recurso que integra o indivíduo ao meio social e também Ihe proporciona uma maior capacidade de autonomia, e assim, de exercer sua cidadania. O princípio fundamental é o de que todas as pessoas com deficiência devem ter suas necessidades especiais atendidas, sendo que no atendimento das diversidades se encontra a democracia.

O autor ainda garante que é no contexto de luta pela igualdade de condições de acesso e permanência com qualidade, que "se norteia a proposta de inclusão e se fundamentam os princípios da prática inclusiva, a qual almeja a construção da cidadania e da democracia" (MARTINS, 2006, p. 49).

A escola inclusiva requer o reconhecimento das diferenças, proporcionando aos estudantes uma aprendizagem de qualidade e fornecendo condições de acesso e permanência para todos. Considerando as políticas públicas educacionais brasileiras em vigência, esses são os grandes desafios do cenário educacional brasileiro: modificar ações para garantir que todos sejam incluídos e aprendam a partir de suas possibilidades.

Pacheco (2007) aponta que o termo educação inclusiva faz referência às inúmeras tentativas, por vezes frustradas, de atender à diversidade total das necessidades educacionais dos estudantes. Por isso é importante que a equipe gestora apoie práticas inovadoras e saiba buscar apoio nos setores por meio de um trabalho colaborativo entre equipes intersetorias para a melhoria do ensino público, desenvolvendo uma estrutura compartilhada entre educadores, profissionais e famílias.

Silva e Facion (2009), salientam que a inclusão estabelece, para o sistema educacional, desafios, como: conscientização da sociedade em geral; investimento em formação continuada de professores; estruturação de métodos, técnicas e recursos; envolvimento da família e da comunidade, além da articulação intersetorial. 
Santos (2011) alega que a partir da proposta de inclusão a escola precisa passar por mudanças em sua organização, como por exemplo na forma de ensinar e avaliar os estudantes, adaptações arquitetônicas e mobiliarias, formação de profissionais aptos para atender a diversidade. $\mathrm{E}$, todas essas mudanças estão diretamente relacionadas ao papel da equipe gestora.

Conforme dito anteriormente, o papel da equipe gestora escolar é fundamental para o bom desempenho da escola. Os profissionais da educação atuantes nas escolas devem concentrar esforços em refletir e (re) descobrir novas formas de ensinar e de aprender, constituindo assim uma cultura inclusiva no contexto escolar.

\section{CONCLUSÃO}

Vivenciar a realidade escolar tem sido extremamente importante para perceber quais são os reais entraves encontrados por uma instituição que se dispõe a oferecer um processo de ensino e de aprendizagem de qualidade a todos os seus estudantes, suas lutas para estabelecer parcerias, redes de apoio e a intersetorialidade conforme prevê a política pública educacional brasileira.

Quando a equipe gestora torna-se realmente aberta a um processo democrático, pode desenvolver ações para a efetivação dos princípios da educação inclusiva, por meio da articulação intersetorial. $O$ trabalho colaborativo entre equipe gestora e setores intersetorias, que vise contribuir com as carências das escolas, pode trazer benefícios tanto para as perspectivas teóricas, quanto práticas, voltadas a educação especial na perspectiva da educação inclusiva.

Mediante a pesquisa observamos que a equipe gestora tem refletido sobre sua própria prática, gerando uma consciência de que é possível reivindicar por políticas educacionais em prol do sistema, bem como tornar uma aula inclusiva dentro das possibilidades de uma escola pública.

\section{REFERÊNCIAS}

BRASIL. Educação inclusiva: a escola. Brasília: Ministério da Educação, Secretaria de Educação Especial, 2004. v. 3.

. Ministério da Educação. Secretaria de Educação Especial. Política Nacional de

Educação Especial na perspectiva da Educação Inclusiva. Brasília: MEC/SEESP, 2008.

LUDKE, M; ANDRÉ, M. E. D. A. Pesquisa em Educação: abordagens qualitativas, São Paulo: EPU, 1986.

MARCONI, M. A; LAKATOS, E. M. Metodologia do Trabalho Científico. São Paulo: Atlas, 1992.

MARTINS, A. E. M. Representações de docentes sobre a inclusão de alunos com deficiências na rede municipal de ensino. 2006. 150 f. Dissertação (Mestrado em Psicologia) - Faculdade de Ciências e Letras, Universidade Estadual Paulista, Assis.

PACHECO, J. et al. Caminhos para a inclusão: um guia para o aprimoramento da equipe escolar. Porto Alegre: Artmed, 2007.

RICHARDSON, R. J. et al. Pesquisa social: métodos e técnicas. 3. ed. 14. reimpr. São Paulo: Atlas, 2012.

SANTOS, R. R. S. Gestão Escolar para uma Escola Inclusiva: conquistas e desafios. Dissertação (Mestrado em Educação). 90 f. Universidade do Oeste Paulista, Presidente Prudente/SP, 2011. 
SILVA, M. F. M. C.; FACION, J. R. Perspectivas da Inclusão Escolar e sua Efetivação. In: FACION, J. R. Inclusão Escolar e suas Implicações. 2 ed. Curitiba: Ibpex, 2008.

UNESCO. 48th International Conference on Education - Conclusions and Recommendations. Geneve: IBE, 2008. 